\title{
¿Cuál sería su actitud terapéutica?
}

\section{What would your therapeutic approach be?}

\author{
Elena Hens-Aumente ${ }^{a}$, Manuel Leopoldo-Rodado ${ }^{a}$, Pedro Infante-Cossío ${ }^{a, *}$ y \\ Azahara Martínez-López ${ }^{b}$ Alberto García-Perla-García ${ }^{a}$ \\ a Servicio de Cirugía Oral y Maxilofacial, Hospital Universitario Virgen del Rocío, Sevilla, España \\ b Servicio de Anatomía Patológica, Hospital Universitario Virgen del Rocío, Sevilla, España
}

Un varón de 19 años, sin antecedentes médicos de interés, fue remitido desde el servicio de Medicina Interna de su Hospital Comarcal de referencia por presentar una tumoración en la región lateral cervical izquierda de crecimiento progresivo durante los últimos 6 meses. A la exploración se le había detectado un nódulo fijo, sobre el tercio medio-tercio inferior del músculo esternocleidomastoideo, sin afectación cutánea,

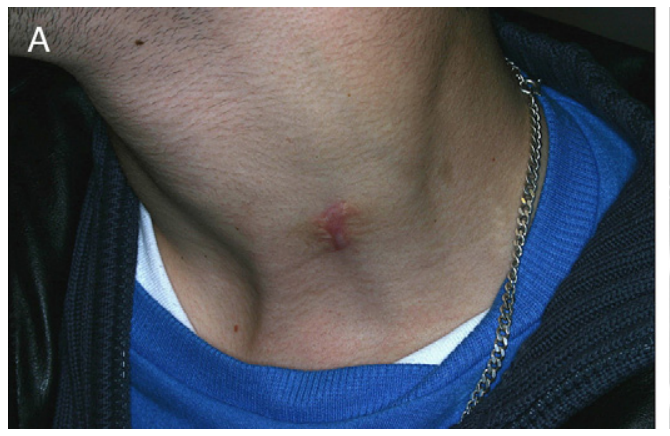

vascular. El índice proliferativo ki-67 está en torno al 10\%. Son negativas las inmunotinciones con desmina, AE1-AE3, EMA, CD99, CD57, CD117 y HMB-45».

El paciente fue derivado al Servicio de Cirugía Oral y Maxilofacial del Hospital Virgen del Rocío (Sevilla) donde, a la exploración, se apreció una tumoración indurada, no dolorosa, bajo una cicatriz hipertrófica que se correspondía a la

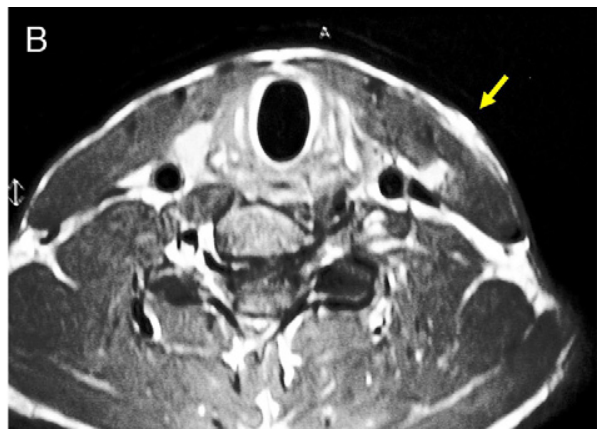

Figura 1 - A. Imagen preoperatoria de la lesión localizada sobre el tercio medio-inferior del músculo esternocleidomastoideo; se visualiza cicatriz producida por la toma de biopsia en el Hospital Comarcal desde donde nos fue remitido el paciente. B. RNM axial que muestra una lesión de $3 \times 2 \mathrm{~cm}$ en el margen posterior del tercio inferior del músculo esternocleidomastoideo (flecha).

de unos $3 \mathrm{~cm}$ de diámetro y no doloroso espontáneamente. En el servicio de Cirugía General realizaron una extirpaciónbiopsia de la lesión, con el resultado histológico de «sarcoma miofibroblástico de partes blandas de bajo grado de malignidad de $2,5 \mathrm{~cm}$, que contacta con bordes de extirpación y que parece iniciarse en el músculo estriado». El estudio inmunohistoquímico informó de «células tumorales con positividad generalizada e intensa para la actina muscular lisa, moderada para vimentina, focal e intensa para actina muscular especifica y S-100, con CD31 y CD34 se revela una prominente red biopsia previa realizada (fig. 1A). Se solicitó una TC de rastreo oncológico y una RNM cervical. La TC de tórax y abdomen fue negativa, no evidenciando metástasis a distancia. En la RNM se informó la presencia de una lesión de $3 \times 2 \mathrm{~cm}$ en el margen posterior del tercio inferior del músculo esternocleidomastoideo, y ganglios laterocervicales múltiples con aumento patológico del yugulodigátrico izquierdo (fig. 1B). El paciente fue valorado en el Comité Multidisciplinar de Tumores de Cabeza y Cuello, donde se consensuó la decisión terapéutica. doi:10.1016/j.maxilo.2011.06.004

\footnotetext{
* Autor para correspondencia.

Correo electrónico: pinfante@us.es (P. Infante-Cossío).
} 